\title{
Investigation on the Application of Constitution Art in Costume Design
}

\author{
Lin Xiao \\ Jiangxi Institute of Fashion Technology, Nanchang, 330000, China
}

\author{
Keywords: Costume design, Constitution Art, Artistic form
}

\begin{abstract}
Costume design is an industry of art, and many crowd has different understand on this stuff and improves the development of this industry. The constitution art refers to design costume through plane composition, three-dimensional construction and two dimensional desgin. This paper would make an detailed analysis on this artistic method of costume design, and is important to learn the basic constitution and art comcept of costume design.
\end{abstract}

\section{Introduction}

Constitution art is one of the artistic form of the time development, the initial artistic schools come from German and it refers to many contents and industries, such as optical, mechanical, geometry and psychology, and also play an important role in the area of costume desgin. As the time develops, constitution art becomes focus on visual rules and aesthetic principle. The visual rules is required by the modernized design and also be the key element of visual language and thought, and it has influenced the industrial structure design and architectural design and costume design and environmental design a lot. So, constitution has been the guidance and theoretical basis of the most damain design. And this paper would make an ayalysis on the application of comstitution art in costume design and explain the characters of the art.

\section{The component of costume design}

In costume design, the material and space are the two important elements of constitution art, and the final form is the construction of this two elements.

\section{Space element}

During the design process, we could use lines to form a wireframe which could produce a sense of space, and at the same time, the used plane material could produce a sense of static. So we connect the material of linellae with the plane materielwill contruct a basic structure. The characters of this structure are virtuality and reality combination, partly hidden and partly visible, and movement clear, all these would lead to strengthen the whole irregular effect and make more spaciousness. For example, when using constitution art in design, we design warpage, hollow out and incision with shell fabric, it could shape shell fabrics to make ite more spaciousness.

\section{Material element}

In costume design, we usually use soft material, and the usage of plane materiel is the main element of costume design, and also the wire rod and bulk. But the using effects of bulk is not very good, so the wire rod is priority ${ }^{[1]}$. The most of material are cotton, gunny, silk and chemical fiber, these textile materials could be mixed, and contruct a space surface in which every material could be transfered mutually. There are some similarity with the home design, the incision of bulk could form face structure which has bad stability and rigidness but with good flexibility, this sense could give a feeling of warmth and relieve. As follows are some detailed arguments about the graphic design methods.

\section{The application of graphic design methods in costume design}

The graphic design is a common method of costume design, it could integrate every design elements, such as point, line, plane and the colour, in the costume design. This way could produce a sense of package, and also beautify the human body. In consideration of its inherent characteristics, 
there are always some problems that those point, line, plane and the colour break away from the three-dimensional effect, so it is also the graphic effect. For this application of graphic design is convenience, and price is suitable, so it has been the introduction to the basic. Only master those elements of graphic design, you could try something professional.

\section{The application of points in graphic design}

The points have geometrical significance, could express the width, length and thickness, and also attributes to shape artistic forms. In consideration of there are no limits on width, length and thickness in plastic arts, the usage of points could not convey visual effects. Therefore, points could only play a certain function of positioning and spaciousness, and different points have different visual effects.

The points uses a lot. For example, floriation, buckle and zippers would use this. Even the shape, material and structure are different and have different visual effects, but they would appear in costume design with unique form. For example, the silk flowers and stripe are essential, and it could be expressed in the way of buckles, it is not only satisfy the practical character, but also achieve esthetic effects of buckles ${ }^{[2]}$. As to the ornamental of the shirt collar and waist, seeds use frenquently. Thus, points use frenquently and have its own features. The prefer style of the traditional Chinese costume are loose, liberty and concise, and also the clipping style is the chinese one, for example, the common pattern of embroidery "Ru-Yi" applies a style of roundness in structural configuration and colour harmony which implies propitious and safeness.

\section{The application of lines in graphic design}

The points could change to lines according to certain rules. Lines are divided into functional lines and decorative lines. For example, a row of buttons in placket front could produce a sense of intense, and also a sense of angled strokes which is not very towering. The same way in the dress design, the princess line could make waist elasticized and chest lift up, which make highlights women's three-dimension curve, this is the reason of the pupularity of dress. The other thing is the belt with high practical and decorative, and could have different decorative effects. The application of thickness, right or wrong, length and segmentation in the midcourt line would have different implications. The costume with same materials, would produce different visual effects with different cutting line of colour $^{[3]}$. Because the cutting lines would produce different visula effects for the materials silk or soft or mental. The oblique line has a significant effects in sports clothes, it will produce a dynamic effects instead of elegant and mystery of wvening dress. For example, there are always have horizontal effects in the male's clothing on the chest which will produce a sense of strength; on the opposite, there are also a line in the female's clothing on the chest, but it has different in curve. So, we need to consider the line application in costume design.

\section{The application of planes in graphic design}

The gather of lines is planes. The planes is the main element, and is the most attractive thing, and form a lot representative patterns. For example, the shape ' $A$ ' could ornament the shoulders and neckline, and constitute triangle-shaped pattern with the lower hem. And the shape ' $\mathrm{O}$ ' could constitute a round structure with the decoration of the neck, shoulder and the lower hem. In consideration of that planes have strong visual effects, and rich language, so the application of planes in costume design is very improtant. The top fashion designer, Christiom Dior is good at using of outline and the whole plank structure, most of his productions are modified constantly. For example, since the second world war, the economy starts to recover and most females are trying to break away from those military uniform and begin to chase some elegant and temperanmental costume. On the basis on this background, Dior pushes out the new look costume successfully, this kind of costume could not only reveal their beautiful curve, and its lower hem become more loose and sway which contrasts great with the military uniform, and literate females in cloting.

\section{The application of two-dimensional design method in costume design}

The two-dimensional design is a commin method of the three-dimensional structural design and called embossment technology. This method refers to gather those planes, and highlightthe confront structure. It could be divided high relief, bas-relief and low relief, and also have many methods, such 
as intaglio and cavetto. The two-dimensional design could produce more graphic effects and express more effects, and also it is high operability and practicability.

\section{The application of line pressing in costume with filling material}

The line pressing in costume with filling material is one two-dimensional design, and is very practical. The mainly useage in the deathers and downs and acrylic fibers, we regard is as a kind of filling material, and by this way, the material could be more solid and three-dimensional effects.

The quiltedstructure requires very strictly, and most of lin pressing are geometric figure, such as diamond and square, and it is easy to sew, but very effective, so it is suitable for the youngsters. However the cost of shaping is high because there a great different between pattern and shape. And some costume have strict requirements for the visual and tactus, they make some improvements by the two-dimentional design method and adjust some parts, such as neckline and sleeve; and some costume make a shape of 'square' in neckline and sleeve, and use block plaids in other parts; as to the sweaters, the acupuncture therapy and those geometric pattern are different which may strengthen the infectivity and persuasiveness.

\section{The application of pleat in costume design}

In costume design, the management on pleats could make concavo-convex texture, is one effective method of two-dimentional design. Tying the knot has a strong representative, in consideration of this fact, the embroidery of knots looks well-aligned and stereoscopic impression. It could not only achieve the decorative effect, but also save time ${ }^{[5]}$. The embroidery on knots are popular in traditional costume, in the parts of chese, shoulder and waist, could be more decorative. As the time develops, the embriidery on knots have changed to more forms, such as, the frequency of processing from both the front and the back, the order of knots, and the shape from the previous four points which reserves the previous visual effects and tactile sense. And at the same time, tying the knots is a part of elasticity which make the costume more comfortable. Then embroidery on knots has an important characteristic that tighten part, which could help to combine its aesthetic property and practicality.

\section{The application of embroidery in two- dimensional design}

Out country is a multinational country, there are four areas in embroidery, such as Sichuan embroidery, Hunan embroidery, Guangdong embroidery and Suzhou embroidery. These embroidery are about rich subject matters and various contents, and two- dimensional design has strengthened the process of beauty. Especially the application of pearly embroidery strenghten are popular for the reason that these sequins are reflective and could make human body produce a sense of visual effects. Many costume designers would interpretate the magic of costume by using pearly embroidery. For example, the famous drawing master, Van Gogh's "the Sunflower" and Picasso's 'Peace Dove' all reflect their magic by its costume and its modeling is pearly two- dimensational design. Meanwhile, this is an expression of our traditional embroidery in material and development direction. Usually, embroidery always reveal in decoration positions of costume, such as brisket, back waist and sleeve, would improve costume's art skills.

\section{The application of three-dimensional design method in costume design}

Make an modeling on a three-dimensional obkect on the basis of graphic design, it could achieve three-dimensional effects, and make an transformation from the plane to three-demensional object. The process of design of every costume is from complicated to simple, it would be three-dimensional effects if we combine costume with body. So, costume could not live without human. Even the process of three-dimensional design is the same with the graphic design, but the modes of thinking are different, and three-dimensional design is more of intuition. In costume, we could use geometric construction to design the partial accessory, and make three-dimensional effects with its lower hem and zipper. In addition, most of the costume in 'the carnaby street' apply the model of three-dimensional decoration. And some plastic pipe, air balloon and metal block are used in costume. Therefore, the application of three-dimensional design could improve its three-dimensional effects. 


\section{Summary}

This paper makes an analysis on the application of constitution art in costume design, and also investigate the components of costume design, the application of graphic design and three-dimensional design. If we want to strengthen costume's art skills and enrich design pattern and promote the area of costume design, we need to imitate more about constitution art which is important for the costume design points, shell fabric design and colour harmony.

\section{References}

[1] Naihua Zhang, Investigation on the deconstructvism of costume design----the application of 'deconstructvism' in costume design. Art Circle,2012(3):104-104.

[2] Shenglan Chen, Discussion on the combination between skin texture and deconstructvism: the printmaking of Yingtian. The journal of Changchui college of education. 2013,29(16):68-69.

[3] Liu Feng. The reference of 'national art'-the application of dress decoration of bai ku yao in local artistic design courses. Art Panorama,2013(8):162-163.

[4] Chongqiong Ding, Haiping Tan, The simple analysis on the new formation teaching system-teaching practice of three dimensional structure in artistic designing, Northern Literature(end of the mouth),2013(1):143-144.

[5] Hui Yu, The establishment of evaluation system on knowledge-based employee on the basis on the collaborative value chain-take clothing enterprises for example. Jiangxi Social Sciences,2013(2):215-219. 